\title{
Focus on Infertility-Women's Experiences of Using Social Media: A Qualitative Study
}

\author{
Taina Sormunen ${ }^{12 *}$, Klas Karlgren1,3,4, Bjöörn Fossum1,5, Arthur Aanesen,,6, \\ Margareta Westerbotn ${ }^{1,5}$
}

\begin{abstract}
${ }^{1}$ Department of Clinical Science and Education, Karolinska Institutet, Södersjukhuset, Stockholm, Sweden ${ }^{2}$ Department of Health Promoting Science, Sophiahemmet University, Stockholm, Sweden

${ }^{3}$ Department of Learning, Informatics, Management and Ethics, Karolinska Institutet, Stockholm, Sweden ${ }^{4}$ Department of Health and Functioning, Western Norway University of Applied Sciences, Bergen, Norway ${ }^{5}$ Department of Nursing Science, Sophiahemmet University, Stockholm, Sweden ${ }^{6}$ Sophiahemmet Hospital, Stockholm, Sweden
\end{abstract}

Email: ^taina.sormunen@shh.se

How to cite this paper: Sormunen, T., Karlgren, K., Fossum, B., Aanesen, A., \& Westerbotn, M. (2021). Focus on Infertility-Women's Experiences of Using Social Media: A Qualitative Study. Open Journal of Social Sciences, 9, 382-395.

https://doi.org/10.4236/jss.2021.95020

Received: April 8, 2021

Accepted: May 16, 2021

Published: May 19, 2021

Copyright $\odot 2021$ by author(s) and Scientific Research Publishing Inc. This work is licensed under the Creative Commons Attribution International License (CC BY 4.0).

http://creativecommons.org/licenses/by/4.0/

(c) (i) Open Access

\section{Abstract}

Background: Social media have slotted firmly into the mechanics of daily life, affecting people's everyday interactions, and working life. Access to the Internet has changed the way people search for information, manage health and illness, and how they relate to each other. Persons affected by infertility are likely to search the Internet to obtain infertility-related information and social support. However, evidence is needed regarding the way in which the target group uses the Internet in infertility-related issues. The aim of the study is to describe infertile women's experiences of using social media focusing on infertility. Methods: This study is based on qualitative semi-structured telephone interviews with seven women. The interviews were conducted between May 2020 and November 2020 and were audio recorded and transcribed verbatim. Collected data were analyzed using thematic analysis. Results: Two themes were constructed from the data: Invaluable venue and Opportunity ot choice. The women used social media focusing on infertility to support each other, to find infertility-related information and for fellowship and solidarity. Usage of social media forums was a part of everyday life and different forums were used, depending upon where the women were in the treatment process. Further, decisions about choice of group were based on which age groups were targeted and geographical location. Conclusion: Infertility is one of the most stressful events in life and is associated with a rollercoaster of emotions. The use of social media focusing on infertility was experienced as positive, providing valuable information, support, eliminating loneliness and being a 
breathing space. Different forums were used depending on where the women were in the treatment process.

\section{Keywords}

Female, Infertility, Social Media, Thematic Analysis

\section{Background}

Infertility is a chronic health disorder associated with a rollercoaster of emotions (Cousineau \& Domar, 2007). Worldwide, infertility is estimated to affect between 8 and 12 percent of reproductive-aged couples (Ombelet et al., 2008). The experience of infertility can be unforeseen, traumatic, may be considered as a life changing experience (Bell, 2013; Hinton et al., 2010). It may be comparable to other major life stressors, such as, grief, chronic disease and divorce (Benyamini et al., 2009).

Social media have permeated daily life, affecting people's everyday interactions and working life (van Dijck \& Poell, 2013). Use of the Internet has transformed the way that people collect information and attempt to deal with suffering from disease and relate to each other (Pew Research Center, n.d.-a). Social media focused on infertility may offer solidarity, infertility-related information (Kahlor \& Mackert, 2009; Malik \& Coulson, 2010a), provide support (Slauson-Blevins et al., 2013) and reduce social isolation (Sormunen et al., 2020).

Facebook and Instagram are currently the major social networking sites (Nambisan, 2011). Globally, the highest engagement on Facebook and Instagram is on Wednesdays, which also is the best time to obtain impact (Pew Research Center, n.d.-b). Engagement on Facebook can be assessed by the rate of participation, from being a lurker, who does not partake at all, to a creator whose virtual presence is extremely noticeable (Malik \& Coulson, 2011; Sprout Social, 2020). Members of online groups can gain social capital by reading the content (Ehsan et al., 2019; Lev-On \& Steinfeld, 2015). Both lurkers and active members need familiarity, so that they can engage in a virtual discussion. It may take members some time before they establish a sense of belonging to the group and are comfortable enough to engage and contribute to conversations (Kate Merry \& Simon, 2012; Malik \& Coulson, 2010b). Regardless of the recognized extensive use of the Internet, relatively little is known about how social media focusing on infertility is used. Greater insight and depth through listening to women is, therefore, relevant to further our understanding of this important topic.

\section{Aim}

To describe infertile women's experiences of using social media focusing on infertility. 


\section{Methods}

\subsection{Design}

A qualitative approach utilizing telephone interviews.

\subsection{Sample Size and Participants}

Seven women participated in the study. They were recruited via various social media focusing on infertility (Sormunen et al., 2020). All participants were from different parts of Sweden.

\subsection{Data Collection}

\section{Interviews}

Seven semi-structured telephone interviews were conducted between June 2020 and November 2020 by the first author (TS). Due to the COVID-19 pandemic, it became necessary to conduct interviews by telephone. The original project design called for face-to-face interviews. Prior to the interviews, the participants were informed about the research goals and methods, their rights as informants, and that the interviews would be audio recorded. The voluntary nature of their participation was emphasized. Verbal informed consent was obtained from all the participants. The duration of the interviews was approximately 30 minutes. The first interview was regarded as a pilot interview (Polit \& Beck, 2016) and was included in the study since no subsequent changes were made in the interview protocol.

Interview schedule

The interview schedule included questions that were in line with the aim of the study and began by asking participants to describe their experiences of using social media focusing on infertility. Further, the open-ended questions covered various aspects of usage, such as, motivation for involvement, what advantages and disadvantages the women experienced, how they chose forums to be active in and their views about the trustworthiness of online information. Care was taken to ensure that all research questions were addressed in each interview.

\subsection{Data Analysis}

The telephone interviews were transcribed verbatim by the first author (TS). Thematic analysis (TA) with an inductive approach, described by Braun and Clarke (2006) and The University of Auckland (n.d.) was used. TA is a method for identifying, analyzing and reporting themes (patterns) within data and consists of six phases: familiarizing with data, generating initial codes, searching for themes, reviewing themes, defining and naming themes and producing the report (Braun \& Clarke, 2006). The data were read multiple times by the first author for familiarization. The data were systematically coded by using phrases and words to label parts that corresponded to the study aim. Codes were moved back and forth. Then the codes were inductively analyzed and their relationships to each other checked to create meaningful subthemes and themes. Themes were 
mapped, reviewed, and refined to confirm relevance and meaning. The first author (TS) led the analysis process, with the last author (MW) reviewing each stage, as well as defining and naming the final themes. The content was discussed in the research team and agreement was reached regarding the analysis, as suggested by Sandelowski (2000). Quotations were chosen to characterize the themes.

\subsection{Ethical Considerations}

Ethical aspects were discussed in the research team at the planning stage of the study. Risks of distressing participants with previous trauma related to infertility investigation and treatment were cautiously balanced with the benefits which could be gained through extended knowledge about the participants' experiences. The Swedish Research Council's Guidelines for ethical assessment of medical research on humans were followed during the entire research process (CODEX, n.d.). Approval from the Ethical Review Board, Stockholm (EPN Diar.nr.: 2015/2290-31/5) was obtained.

\section{Results}

Two overlapping themes were constructed from the data that represent the participants' experiences of using social media focusing on infertility: Invaluable venue and Opportunity of choice. Each theme includes the differing aspects from the data of the idea it signifies and is made up of several related subthemes illustrating the depth and complexity of the semantic data (Table 1).

The main reasons for using social media that deal with infertility were information seeking and fellowship. For example, information regarding how others have received help, which treatments have been used, if they have succeeded in becoming pregnant and how they have felt during investigations and treatment, were appreciated. Most of the participants that used Facebook were members in closed groups. To get access to the group's posts, you had to apply for membership from the administrator of each group. The participants had been in the Facebook groups from six months up to six years. Most of them joined the Facebook groups in search of information about difficulties conceiving.

\subsection{Invaluable Venue}

The women expressed what they valued the most regarding social media focused

Table 1. Themes and corresponding subthemes.

\begin{tabular}{cc}
\hline Theme & Subtheme \\
\hline Invaluable venue & Breathing space and incognito \\
Source of vital information \\
Support and hope \\
Fellowship and solidarity \\
Opportunity of choice & Part of everyday life \\
& Diversity of practice \\
& Awareness of the credibility \\
\hline
\end{tabular}


on infertility, such as, finding respite, being able to remain incognito, source of information, conveying hope and providing fellowship and solidarity. Social media focusing on infertility were described as a breathing space and incognito where the participants were able to find respite.

"If one has not experienced this, it is impossible to understand. I would have gone crazy if I did not have the people online to discuss it with. I used Facebook and Instagram as a breathing space" (Participant 5)

Also, a place to be incognito when participating in the social media forums. This was expressed as important by the participants. Too large and open forums were described as involving a greater risk of having one's identity revealed.

"This is a sensitive topic anyway. It may be that you know people who are members of the forum and read their posts. This can be a disadvantage." (Participant 1)

For some participants, the search for information about infertility started because they wanted to know other people's feelings about it. Personal stories were a significant source of vital information providing a more human perspective and helped to find others who mirrored their own situation.

The participants were desperate for answers about infertility-related questions. Online social media focusing on infertility were experienced as being able to offer valuable information; about how to get started with fertility treatments, about medication, side effects and different treatment options. To be able to ask questions and get answers 24/7 made the women less worried about their situation.

"There was always somebody on the forum who could explain in simple language what different terms meant." (Participant 2)

Information sought varied, depending on participants' progress through their journey to different infertility treatments.

"I searched for information on different forums and read a lot about it...not to have your own egg cells. How is it? Which clinics can you go to and so on? I would never have tried egg donation if I had not read about it on social media. All the decisions I made were based on that information, from books, TV and social media... not information from a doctor. I did not take any medical facts from the forums, but only the descriptions of experiences." (Participant 6)

Some of the participants had experienced that healthcare professionals at the fertility clinic had delayed the delivery of important information intentionally. The personnel were able to provide answers regarding medical questions. However, questions about emotions, how something feels or is experienced, those answers were felt to be deficient.

"When you are in the middle of this carousel of investigations and treatments you want to be well-informed. Our doctor said we would go through it (information) later as he did not want to make me sadder. But when you are already so exposed and so depressed, it does not matter. They can just as easily tell you; you still feel bad... it is better that they do not withhold it but say straight out." (Participant 4) 
Some participants reported that they had hidden their "problem" of having a child from their family and friends and therefore turned to social media where they could meet other individuals in a similar situation to get support and hope.

"We kept a low profile externally, but then of course we turned to social media. We sought support there and realized that we are not as lonely as we thought we were in this." (Participant 4)

Participants described that postings written by other members conveying hope and comfort were most appealing. To be able to read about other people's successful fertility treatments gave hope that you would also succeed in getting pregnant.

"Above all, you want to hear stories about people who have succeeded. To feel hope. One could find solace and that everything will go well." (Participant 4)

Postings in which the participants could recognize problems of infertility, treatment methods and emotions were often searched for. These postings enabled the participants to maintain an optimistic belief in a successful future.

"If someone writes how they feel and what they have done or what their problem was. If you recognize yourself in the post, it's most pleasing." (Participant 3)

All participants described that social media focused on infertility impart fellowship and solidarity. Being able to make connections with others in the same situation and with similar experiences was described as an advantage. Sharing experiences of the complex trauma of infertility with others can help the one sharing, as well as others in the same situation.

Some of the women made connections with other forum members even in the physical world.

"I sent messages to some forum members and actually got to know some couples there. So, we also have contact outside of social media." (Participant 3)

\subsection{Opportunity of Choice}

In terms of choice, social media give the users the possibility to choose, for example, which forum they want to get involved in, when to participate, which posting to read/comment on and whether to be active or a lurker.

The women described how they used social media focused on infertility as part of everyday life and the usage followed where they were in the treatment process. Evenings and weekends were the times when participants were most active on social media and some women took the opportunity to use travel time on the bus or subway. Even lunch breaks were opportunities for engagement.

"During the lunch break at work! When I want to have some peace and quiet, I crawl away and scroll. When I get home, I am busy with other things. At work I sit quite a lot at the computer and talk on the phone, so when I get home it is nice to put everything aside. I devote myself to other things." (Participant 4)

The use of social media focused on infertility changes over time, depending on where the women were in the treatment process.

"When you are active during an IVF period... we have done IVF twice and two egg blocks, you are more active in the groups when you are in the process. 
Later you can... put it on ice." (Participant 2)

The women chose groups on social media based on which kinds of treatment they were going through and the progress of the treatment. It was also important to delimit one's participation in order to handle different forums.

"I joined the Facebook group because its members also underwent IVF treatment, which my husband and I were going to do. I felt that this was a group where I could get information and meet others who were in the same situation. I then joined a pregnant group, for us who had become pregnant via IVF... only women could be members in that group. And it was a criterion that I thought was nice." (Participant 1)

Additional selection criteria for the social media were participants' geographical location and age group.

"There is also a Facebook group for IVF, for those living in Stockholm. I joined a Facebook group for those over 40. Too often, many members are quite young. We who are a little older... we are older. We have a different kind of anxiety. Then it can be quite nice to talk to those who are the same age. It's a different kind of psychological stress. To be in this situation than when you are 29 and maybe doing treatment, then you have a few years on your side. We do not have that!"(Participant 7)

Social media were also used as diaries to process experiences of infertility. The women shared their feelings with others and received mutual support. Social media were described as "a journal that talks back to you".

"On Instagram I started a new account for my IFV journey, where I described my story. It was like a diary. So, I got a lot of followers, who liked and commented my postings. And then I found new accounts, which were like mine." (Participant 5)

Information that the participants shared through their postings dealt with feelings, meetings with healthcare, symptoms, collection of eggs and where the women were in the process.

"Treatment process and how the treatment felt. How I felt afterwards and... it can be a long process before succeeding with the treatment. It is a roller coaster back and forth... as you have that anxiety all the time as well. Will the treatment be successful or not... and how will it be then? That is the kind of information Im sharing." (Participant 1)

Various forums were used as a diversity of practice in different ways depending on current need. Social media groups focused on infertility could be found by listening to Pods or by searching the Internet. Some women who were on the Facebook groups switched to Instagram and moved their discussions to private Instagram accounts instead. Leaving the Facebook groups were sometimes perceived as betrayal by remaining members. Large Facebook groups could be perceived as more superficial than smaller groups; in smaller groups, participants were able to share more about their personal information. Most participants were, or had been, active in different groups focused on infertility on Facebook. One of the participants had her own blog, but several of them read and followed 
blogs run by others.

"I was in these larger Facebook groups, both closed and open ones. However, I follow some accounts on Instagram, especially people I have come in contact with. So, we follow each other. Then there are some American Instagram pages that I am following. But they are not the same thing as the Swedish Facebook groups." (Participant 4)

Social media were also used as channels to inform friends and acquaintances about their problems having a child.

"I see Instagram a bit like a diary, a kind of filter, like having a conversation partner, which may not be visible, but you can share your thoughts in a different way than you do on Facebook. My Instagram account can be seen only by few persons, close friends, colleagues and my family. I am more open there and I am straighter and do not have to explain." (Participant 7)

On social media, the women could choose which posts they read or did not read. One participant did not read posts containing other persons' treatment successes.

"If you are in a group and you have not become pregnant and read about someone who has become pregnant or had a child, you do not want to read that! In any case, I do not want to read that! And even if your friends... or colleagues are pregnant, I delete their posts. I remove them from my social media... I do not want to read that." (Participant 3 )

Participants wished there were alternatives to social media, such as, forums connected to the clinic where the patients could get help quickly. Further, organized groups in the physical world, where you could meet others in the same situation.

"I was told by the healthcare services that infertility is not a disease... no life-threatening disease. You do not die from it was the reply when I asked for conversational support. Somewhere to go and ventilate with others and permission to scream and cry and laugh. It is one thing to talk on the Internet, but I think it is important to exchange experiences with others. Sit around a table, have a cup of coffee and talk." (Participant 4)

The women expressed that they were cautious when looking for reliable information on the Internet; they had awareness of the credibility of the content.

"You should not simply trust what is written on social media... it is ordinary people who write. They have similar experiences as I have. It is me who... must be a little careful... you must be. And you should consult healthcare and not just ask and get answers in a Facebook group. People can interpret and experience things differently." (Participant 1)

When it comes to the authenticity of the personal stories, the participants trusted the experiences of infertility that were described by other forum members on social media.

"I wanted to seek experiences on the forums, people who had gone through the same treatment as me. And I do not think that those who write about expe- 
riences are bluffing. I pretty much trusted that their experiences were true and not fake." (Participant 6)

As there are different treatment procedures, participants reported that the information that appears on social media does not apply to everyone. For example, medicines that are prescribed for an individual and involve different doses and times. The women reported that they always consulted the physician at the fertility clinic for reliable information.

\section{Discussion}

The purpose of this study was to describe infertile women's experiences of using social media focusing on infertility. Data analysis revealed that the women considered there to be a range of significant benefits from their online experiences, which appeared to aid their ability to cope with challenges surrounding the diagnosis and treatment of infertility. Online social media focusing on infertility were described by the women as a breathing space, in which they could receive support and gain access to vital information regarding infertility evaluation and treatment, as has been evidenced earlier by Malik and Coulson (2008). In addition, social media focused on infertility conveyed information about the feelings and experiences of other people in the same situation, which was highly valued by the women. Our findings are in line with Stenström's (2020) research results, indicating that social media might be a lifeline for women struggling with infertility. It also may be easier to write down thoughts and emotions than to talk about them (Rains, 2014).

Being able to participate incognito in the online forums was described as one of the best features. As several of the women expressed that they did not want to reach out to those around them, they were able to ventilate and find resources to promote their psychological well-being on the forums while still feeling a sense of human contact. These findings have been evidenced previously, for instance, by Kahlor and Mackert (2009), Malik and Coulson (2010b), Slauson-Blevins et al. (2013), Sormunen et al. (2020) and Nambisan (2011).

While the social media forums offer possibilities of sharing valuable information and support, they also risk spreading misinformation (Chou et al., 2018). The participants in our study were aware that social media writers are ordinary people and that they themselves had to be careful about what information to trust. For medical issues, it is best to consult a caregiver at the clinic. According to the participants, the desirable forums would be those connected to the fertility clinic, with the expertise from expert health professionals.

Von Thiele Schwarz (von Thiele Schwarz, 2016) states that access to social media can change the relationship between patients and caregivers. Patients may be given more responsibility as they use other sources of information. Co-care means that care providers' resources must be combined with the resources that patients use. Swan (Swan, 2009) points out that medical doctors may not have the time to keep up with all aspects of new research in the fields they cover. Pa- 
tients may therefore have greater knowledge about their condition than health care professionals (Snow et al., 2013).

In Sweden, 98 percent of households have access to the Internet and 95 percent of Internet users access it via a mobile phone (Svenskarna och internet, 2019). Therefore, it is possible for the women to use infertility social media whenever they have a need of it, regardless of time and place. The results in the present study show that the women were more passive in the beginning when joining forums, in order to examine the terrain.

The new perspective from the results of this study is that the choice of forum may be also influenced by the age of the forum members and their geographical location. The reason for this may be that their problem with infertility may be the same as that of others. However, the experiences of stress may differ depending on age. One reason may be the women's awareness that the older they get the quicker fertility decreases (Committee Opinion No. 589, 2014) and that there is a time limit when it comes to fertility treatment. The younger women have more time to get treatment. The age of the forum members, and to whom the forum is aimed geographically, may therefore be important criteria when choosing a forum.

\section{Methodological Considerations}

There are several potential methodological limitations to the present study to consider. Firstly, the results represent only those women who chose to contribute to this study, therefore the sample might not satisfactorily represent a wider population. The extent to which the women who chose to participate are representative of females affected by infertility remains unclear. The sampling strategy utilized social media focused on infertility as a key forum for recruitment. This may have led to those early on in their pursuit of infertility information being less likely to participate. Besides, sampling purposively focused on people with specific experiences of using social media focused on infertility. To recruit additional participants, snowballing was used. Polit and Beck (Polit \& Beck, 2016) point out that snowball sampling may have distinct advantages, such as, it is practical and the researcher may have an easier time creating a trusting relationship with new participants (Polit \& Beck, 2016). Another limitation of this study is its geographical focus. As this study included only Swedish women, we suggest that to gain an international perspective, similar studies should be conducted in other countries.

Seven women participated in this study, which might be a weakness of the study. Their mail addresses were collected in 2017, when we carried out our previous study (Sormunen et al., 2020). Several of the mail addresses were not functioning when contacting them again in 2020. Malterud et al. (Malterud et al., 2016), propose the concept of information power to guide satisfactory sample size in qualitative studies. Information power depends on the aim of the study, sample specificity, use of established theory, quality of dialogue and analysis 
strategy. The aim of this study was to describe infertile women's experiences of using social media focusing on infertility. This aim can be considered as quite narrow and therefore seven participants were enough to address it. Regarding sample specificity, the participants had characteristics that are highly specific for the study aim. The quality of interview dialogue depends on interaction between researcher and participant (Malterud et al., 2016), and in the present study the communication was clear and strong. Thematic analysis was used to analyze the data and the ambition was not to cover the whole range of phenomena, but to present patterns appropriate to the study aim.

Due to the COVID-19 pandemic, the data were collected utilizing telephone interviews. Creswell \& Poth (2016) point out that using telephone interviews is suitable when the respondents cannot be accessed otherwise. Some methodological strengths of qualitative telephone interviews are, e.g. increased privacy for respondents, perceived anonymity and reduced distraction (Lechuga, 2012). Consequently, telephone interviews were appropriate to study this vulnerable group and make their voices heard. Guest et al. (2006) advocate the view that from one interview upwards is satisfactory for a qualitative study, depending on the target audience characteristics, expertise of the participants and research scope.

\section{Conclusion}

The use of social media focusing on infertility was experienced as positive and supportive. Also, the forums could be used for instant information seeking and finding persons in similar situations. The age of the forum members and for whom the forum is intended geographically, may be central criteria when selecting a forum focusing on infertility.

\section{Relevance to the Clinical Practice}

It is essential for personnel at clinics to assess whether persons with infertility are adequately supported.

\section{Acknowledgements}

The authors would like to thank the participants for taking part in this study.

\section{Authors' Contributions}

Study design: TS, KK, BF, AA, MW; Data collection TS; Data analysis: TS, MW; and manuscript preparation: TS, KK, AA, BF, MW. The authors read and approved the final manuscript.

\section{Funding}

The Sophiahemmet Foundation of Clinical Research supported this study by a grant regarding the design of the study, data collection, analysis and writing the manuscript. 


\section{Availability of Data and Materials}

The data generated and/or analysed during the current study are not publicly available due to confidentiality and risk for identification of participants but are available from the corresponding author on reasonable request.

\section{Ethical Approval and Consent to Participate}

The Ethical Review Board, Stockholm (EPN 2015/2290-31/5) approved the study and the procedure of informed consent. Prior to the telephone interviews written information about the study and participation were send to the participants by e-mail. The participants were given opportunity to ask questions about the study before the data collection. Informed consent was obtained orally from the participants before commencing the telephone interviews. Answering the questions was considered as giving informed consent to participation.

\section{Conflicts of Interest}

The authors declare no conflicts of interests.

\section{References}

Bell, K. (2013). Constructions of "Infertility" and Some Lived Experiences of Involuntary Childlessness. Affilia, 28, 284-295. https://doi.org/10.1177/0886109913495726

Benyamini, Y., Gozlan, M., \& Kokia, E. (2009). Women's and Men's Perceptions of Infertility and Their Associations with Psychological Adjustment: A Dyadic Approach. British Journal of Health Psychology, 14, 1-16. https://doi.org/10.1348/135910708X279288

Braun, V., \& Clarke, V. (2006). Using Thematic Analysis in Psychology. Qualitative Research in Psychology, 3, 77-101. https://doi.org/10.1191/1478088706qp063oa

Chou, W.-Y. S., Oh, A., \& Klein, W. M. P. (2018). Addressing Health-Related Misinformation on Social Media. JAMA, 320, 2417-2418.

https://doi.org/10.1001/jama.2018.16865

CODEX (n.d.). Rules and Guidelines for Research. http://www.codex.vr.se/en/forskningmanniska.shtml

Committee Opinion No. 589 (2014). Female Age-Related Fertility Decline. Fertility and Sterility, 101, 633-634. https://doi.org/10.1016/j.fertnstert.2013.12.032

Cousineau, T. M., \& Domar, A. D. (2007). Psychological Impact of Infertility. Best Practice \& Research Clinical Obstetrics \& Gynaecology, 21, 293-308. https://doi.org/10.1016/j.bpobgyn.2006.12.003

Creswell, J. W., \& Poth, C. N. (2016). Qualitative Inquiry and Research Design: Choosing among Five Approaches. Thousand Oaks, CA: SAGE Publications.

Ehsan, A., Klaas, H. S., Bastianen, A., \& Spini, D. (2019). Social Capital and Health: A Systematic Review of Systematic Reviews. SSM-Population Health, 8, Article ID: 100425. https://doi.org/10.1016/j.ssmph.2019.100425

Guest, G., Bunce, A., \& Johnson, L. (2006). How Many Interviews Are Enough?: An Experiment with Data Saturation and Variability. Field Methods, 18, 59-82. https://doi.org/10.1177/1525822X05279903

Hinton, L., Kurinczuk, J. J., \& Ziebland, S. (2010). Infertility; Isolation and the Internet: A Qualitative Interview Study. Patient Education and Counseling, 81, 436-441. 
https://doi.org/10.1016/j.pec.2010.09.023

Kahlor, L., \& Mackert, M. (2009). Perceptions of Infertility Information and Support Sources among Female Patients Who Access the Internet. Fertility and Sterility, 91, 83-90. https://doi.org/10.1016/j.fertnstert.2007.11.005

Kate Merry, S., \& Simon, A. (2012). Living and Lurking on LiveJournal: The Benefits of Active and Non-Active Membership. Aslib Proceedings, 64, 241-261. https://doi.org/10.1108/00012531211244527

Lechuga, V. M. (2012). Exploring Culture from a Distance: The Utility of Telephone Interviews in Qualitative Research. International Journal of Qualitative Studies in Education, 25, 251-268. https://doi.org/10.1080/09518398.2010.529853

Lev-On, A., \& Steinfeld, N. (2015). Local Engagement Online: Municipal Facebook Pages as Hubs of Interaction. Government Information Quarterly, 32, 299-307. https://doi.org/10.1016/j.giq.2015.05.007

Malik, S. H., \& Coulson, N. S. (2008). Computer-Mediated Infertility Support Groups: An Exploratory Study of Online Experiences. Patient Education and Counseling, 73, 105-113. https://doi.org/10.1016/j.pec.2008.05.024

Malik, S. H., \& Coulson, N. S. (2010a). Coping with Infertility Online: An Examination of Self-Help Mechanisms in an Online Infertility Support Group. Patient Education and Counseling, 81, 315-318. https://doi.org/10.1016/j.pec.2010.01.007

Malik, S. H., \& Coulson, N. S. (2010b). “They All Supported Me but I Felt Like I Suddenly Didn't Belong Anymore": An Exploration of Perceived Disadvantages to Online Support Seeking. Journal of Psychosomatic Obstetrics \& Gynecology, 31, 140-149. https://doi.org/10.3109/0167482X.2010.504870

Malik, S. H., \& Coulson, N. S. (2011). A Comparison of Lurkers and Posters within Infertility Online Support Groups. Computers, Informatics, Nursing: CIN, 29, 564-573. https://doi.org/10.1097/NCN.0b013e318224b31d

Malterud, K., Siersma, V. D., \& Guassora, A. D. (2016). Sample Size in Qualitative Interview Studies: Guided by Information Power. Qualitative Health Research, 26, 1753-1760. https://doi.org/10.1177/1049732315617444

Nambisan, P. (2011). Information Seeking and Social Support in Online Health Communities: Impact on Patients' Perceived Empathy. Journal of the American Medical Informatics Association, 18, 298-304. https://doi.org/10.1136/amiajnl-2010-000058

Pew Research Center (n.d.-a). Demographics of Internet and Home Broadband Usage in the United States.

https://www.pewresearch.org/internet/fact-sheet/internet-broadband/

Pew Research Center (n.d.-b). Share of U.S. Adults Using Social Media, Including Facebook, Is Mostly Unchanged Since 2018.

https://www.pewresearch.org/fact-tank/2019/04/10/share-of-u-s-adults-using-social-m edia-including-facebook-is-mostly-unchanged-since-2018/

Ombelet, W., Cooke, I., Dyer, S., Serour, G., \& Devroey, P. (2008). Infertility and the Provision of Infertility Medical Services in Developing Countries. Human Reproduction Update, 14, 605-621. https://doi.org/10.1093/humupd/dmn042

Polit, D. F., \& Beck, C. T. (2016). Nursing Research: Generating and Assessing Evidence for Nursing Practice. Netherlands: Wolters Kluwer.

Rains, S. A. (2014). The Implications of Stigma and Anonymity for Self-Disclosure in Health Blogs. Health Communication, 29, 23-31. https://doi.org/10.1080/10410236.2012.714861

Sandelowski, M. (2000). Whatever Happened to Qualitative Description? Research in 
Nursing \& Health, 23, 334-340.

https://doi.org/10.1002/1098-240X(200008)23:4<334::AID-NUR9>3.0.CO;2-G

Slauson-Blevins, K. S., McQuillan, J., \& Greil, A. L. (2013). Online and In-Person Health-Seeking for Infertility. Social Science \& Medicine, 99, 110-115.

https://doi.org/10.1016/j.socscimed.2013.10.019

Snow, R., Humphrey, C., \& Sandall, J. (2013). What Happens When Patients Know More than Their Doctors? Experiences of Health Interactions after Diabetes Patient Education: A Qualitative Patient-Led Study. BMJ Open, 3, e003583.

https://doi.org/10.1136/bmjopen-2013-003583

Sormunen, T., Karlgren, K., Aanesen, A., Fossum, B., \& Westerbotn, M. (2020). The Role of Social Media for Persons Affected by Infertility. BMC Women's Health, 20, 112. https://doi.org/10.1186/s12905-020-00964-0

Sprout Social (2020). The Best Times to Post on Social Media in 2020. https://sproutsocial.com/insights/best-times-to-post-on-social-media/

Stenström, K. (2020). Involuntary Childlessness Online: Digital Lifelines through Blogs and Instagram. New Media \& Society, in press.

https://doi.org/10.1177/1461444820968907

Svenskarna och internet (2019). Meaningful Time Online and the Pros and Cons of Digital Society.

https://svenskarnaochinternet.se/rapporter/svenskarna-och-internet-2019/the-swedesand-the-internet-2019-summary/

Swan, M. (2009). Emerging Patient-Driven Health Care Models: An Examination of Health Social Networks, Consumer Personalized Medicine and Quantified Self-Tracking. International Journal of Environmental Research and Public Health, 6, 492-525. https://doi.org/10.3390/ijerph6020492

The University of Auckland (n.d.). Thematic Analysis: A Reflexive Approach. https://www.psych.auckland.ac.nz/en/about/thematic-analysis.html

van Dijck, J., \& Poell, T. (2013). Understanding Social Media Logic. Media and Communication, 1, 2-14. https://papers.ssrn.com/abstract=2309065 https://doi.org/10.12924/mac2013.01010002

von Thiele Schwarz, U. (2016). Co-Care: Producing Better Health Outcome through Interactions between Patients, Care Providers and Information and Communication Technology. Health Services Management Research, 29, 10-15. https://doi.org/10.1177/0951484816637746

\section{Abbreviations}

IVF: In Vitro Fertilization;

MW: Margareta Westerbotn;

TA: Thematic Analysis;

TS: Taina Sormunen. 